\title{
Even lower is possible: impact of flow rate on safety issues in low flow anaesthesia
}

\author{
Ozden Omaygenc D. ${ }^{1}$, Kepekci A.B. ${ }^{2}$, Telli S. ${ }^{3}$, Karaca I.O. ${ }^{4}$, Yucepur S. ${ }^{5}$, Ozenc E. ${ }^{6}$ \\ 1 Yedikule Pulmonary Diseases and Thoracic Surgery Training and Research Hospital, Dept of Anaesthesiology, İstanbul, Turkey. \\ 2 Meltem Hospital, Dept of Anaesthesiology \& Intensive Care, Istanbul, Turkey. \\ 3 Istanbul University, Dept of Anaesthesiology, Istanbul, Turkey. \\ 4 Istanbul Medipol University, Department of Cardiology, Istanbul, Turkey \\ 5 Suluova State Hospital, Dept of Anaesthesiology \& Intensive Care, Amasya, Turkey. \\ 6 Haseki Training and Research Hospital, Dept of Anaesthesiology \& Intensive Care, Istanbul, Turkey.
}

Goal of Study: We aimed to assess the effect of different flow rates of low flow fresh gas mixtures on hemodynamic state, gas exchange parameters and recovery time during general anaesthesia of urogenital system operations in a single tertiary centre.

Materials and methods: Sixty-two ASA Class I or II patients were enrolled for this study. The whole study population to whom low flow anaesthesia had been administered were subsequently gathered in three distinct -A, high flow, B, low flow, C, minimal flow- groups. Following induction, in all groups, $40 \% \mathrm{O}_{2}, 60 \% \mathrm{~N}_{2} \mathrm{O}$ and 1-2\% sevoflurane mixtures were given in anaesthesia maintenance with a flow rate of $41 /$ min for 10 minutes. Thereafter, flow rate was reduced to $21 / \mathrm{min}, 11 / \mathrm{min}$ and $0.5 \mathrm{l} / \mathrm{min}$ in Groups A, B and C, respectively. In minimal flow group concerning the risk of hypoxia, $\mathrm{O}_{2}$ concentration was enhanced to $60 \%$. Hemodynamic data before and during anaesthesia, additionally, gas exchange and blood gas analysis parameters at 30th minute and before cessation of anesthesia were recorded. Recovery period was observed by a second physician and times of interest were noted.

Results: Demographic characteristics were similar among study groups. Data regarding vital signs, gas exchange and blood gas analysis at the 30th minute and prior to cessation of anesthesia were mostly comparable. As expected, oxygenation parameters in blood gas analysis were significantly higher in group $\mathrm{C}$ during $\left(\mathrm{pO}_{2}, \quad \mathrm{mmHg}, \quad 168.6 \pm 43.9\right.$ vs $165.4 \pm 39.9$ vs $245.5 \pm 51.5, \mathrm{p}<0.001 ; \mathrm{SaO}_{2}, \%, 98.6 \pm 1.1$ vs $98.3 \pm 1.2$ vs $99.2 \pm 0.9, \mathrm{p}=0.019$ ) and at the end of operation $\left(\mathrm{pO}_{2}, \mathrm{mmHg}, 165.6 \pm 41.8 \mathrm{vs}\right.$ $152.7 \pm 64.3$ vs $227.9 \pm 46.7, \mathrm{p}<0.001 ; \mathrm{SaO}_{2}, \%$, $98.1 \pm 1.4$ vs $98.1 \pm 1.2$ vs $98.8 \pm 1.1, \mathrm{p}=0.028)$. Lactate levels were higher at low flow and minimal groups at 30th minute but this difference lost significance before cessation of anesthesia. In any circumstances all values were in normal limits (mmol/l, $1.04 \pm 0.56$ vs $1.29 \pm 0.49$ vs $1.33 \pm 0.46, \mathrm{p}=0.038$ and $1.08 \pm 0.48$ vs $1.27 \pm 0.58$ vs $1.22 \pm 0.52, p=0.623$; respectively)

Aside from this, during operation, inspiratory sevoflurane levels were significantly higher in Group A ( $1.7 \pm 0.6$ vs $1.3 \pm 0.3$ vs $1.3 \pm 0.3, p=0.043$ ). There were no significant differences between the groups in terms of recovery data.

\begin{tabular}{lcccc}
\hline & Group A (n=21) & Group B $(\mathbf{n}=\mathbf{2 0})$ & Group C $(\mathbf{n}=\mathbf{2 1})$ & p value \\
\hline $\begin{array}{l}\text { Time to spontaneous } \\
\text { breathing (min) }\end{array}$ & $0.8 \pm 1.2$ & $1.2 \pm 1.7$ & $1.4 \pm 1.5$ & 0.210 \\
$\begin{array}{l}\text { Time to extubation } \\
\text { (min) }\end{array}$ & $3 \pm 2.4$ & $4.1 \pm 2.5$ & $4.9 \pm 3.7$ & 0.113 \\
$\begin{array}{l}\text { Time to eye opening } \\
\text { (min) }\end{array}$ & $6.8 \pm 4.5$ & $7.3 \pm 3.6$ & $8.2 \pm 3.5$ & 0.500 \\
$\begin{array}{l}\text { Time to verbal } \\
\text { response (min) }\end{array}$ & $9 \pm 5.5$ & $8.8 \pm 3.9$ & $10 \pm 3.8$ & 0.518 \\
$\begin{array}{l}\text { Time to reach a } \\
\text { Modified Aldrete Score } \\
\text { of } 9 \text { or 10 (min) }\end{array}$ & $13.7 \pm 6.8$ & $13.6 \pm 5.2$ & $14.8 \pm 4$ & 0.717 \\
\hline
\end{tabular}

Conclusion: Widespread utilization of low flow anaesthesia is a cornerstone for the evolution of inhalation anaesthesia regarding the cost reduction efforts of public health policies and conservation of the personnels' health and air purity. ${ }^{1}$ From this point of view, it is reasonable to suggest that less is better. Here we report the safety -by means of avoiding hypoxia, acidosis, hemodynamic disturbance and retarded recovery phase- of administering gas mixtures with sevoflurane even at very low flow rates, which meet the needs of modern inhalation anaesthesia.
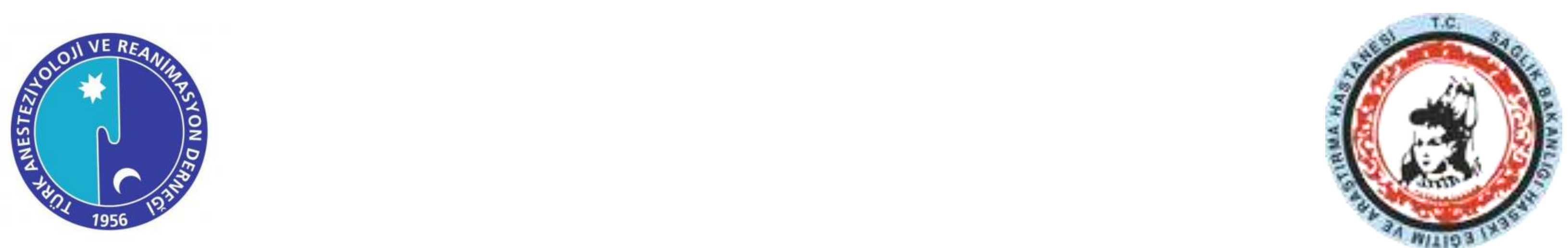